\title{
Peran Ziswaf dalam Memulihkan Ekonomi Umat Akibat Masa Pandemi Covid-19
}

\author{
Choirul Amirudin', Ahmad Fikri Sabiq ${ }^{2}$ \\ Institut Agama Islam Negeri Salatiga \\ Email:choirulamir123@gmail.com ${ }^{1}$,ahmadfikrisabiq@gmail.com ${ }^{2}$
}

\begin{abstract}
This research was conducted with the aim of providing solutions and the role of one the Islamic economic instruments, namely zakat, infaq, alms and waqf which can be applied in dealing with economic problems due to the Covid-19 pandemic. In conducting research, researchers used a library research approach and content analysis techniques. The results of the research that show that Ziswaf can be a solution and role to restore the economy due to the Covid-19 pandemic are as follows: (1) Make each village an UPZ to maximize zakat (2) maximize cash zakat and productive zakat (3) maximize zakat and infaq management (4) providing educational assistance for students affected by Covid-19, which is prioritized for students majoring in sharia economics so that in the future they can educate the public about Islamic economics.

Keywords : Ziswaf, Economics, Covid-19

Abstrak : Penelitian ini dilakukan dengan tujuan untuk memberi solusi dan peran dari salah satu intrumen ekonomi syariah yaitu zakat, infaq, sedekah dan wakaf yang dapat diaplikasikan dalam mengahadapi masalah ekonomi akibat pandemi covid-19. Dalam melakukan penelitian, peneliti menggunakan metode pendekatan studi pustaka (library research) dan teknik content analysis. Hasil penelitian yang menunjukan bahwa Ziswaf dapat menjadi solusi dan peran untuk memulihkan ekonomi akibat pandemi covid-19 sebagai berikut: (1) Menjadikan setiap desa sebagai UPZ untuk memaksimalkan zakat (2) memaksimalkan zakat tunai dan zakat produktif (3) memaksimalkan pengelolaan zakat dan infaq (4) mengadakan bantuan pendidikan bagi mahasiswa yang terkena dampak covid-19, yang diutamakan bagi mahasiswa jurusan ekonomi syariah supaya kedepan dapat mengedukasi masyarkat tentang ekonomi Islam.

Kata Kunci : Ziswaf, Ekonomi, Covid-19
\end{abstract}

\section{A. Pendahuluan}

Perekonomian merupakan suatu hal yang penting bagi perorangan, baik lembaga atau instansi pemerintah dalam kehidupan. Perekonomian sangat berperan penting dikarenakan jika rendahnya ekonomi seseorang maka taraf kehidupan juga rendah. Sebaliknya jika tingginya perekonomian seseorang maka taraf kehidupan seseorang tersebut juga tinggi. Dengan demikian, dalam kehidupan ini tidak bisa terlepas dari persoalan perekonomian. Permasalahan ekonomi tidak pernah habisnya untuk dibahas karena berhubungan dengan angka kekayaan, kesejahteran, pengangguran dan kemiskinan. Kemiskinan menjadi hal yang sangat ditakuti oleh setiap orang karena kemiskinan berdampak kepada permasalahan multidimensional berupa pendidikan, sosial, kesehatan, dan politik. ${ }^{1}$

Isu-isul terkait masalah sosial ekonomi seperti kemiskinan, kelaparan, pengangguran menjadi topik klasik yang belum terselesaikan di Indonesia. Teori ekonomi modern menyatakan bahwa pertumbuhan perekonomian akan mengurangi kemiskinan dan meratakan

\footnotetext{
${ }^{1}$ Nufi Mu'tamar Almahmudi, “Implikasi Instrumen Non-Zakat (Infaq, Sedekah, Dan Wakaf) Terhadap Perekonomian Dalam Perkembangan Hukum Ekonomi Syariah," Al Huquq: Journal of Indonesia Islamic Economic Law 2, no. 1 (2020): 30-47.
} 
pendapatan menjadi sangat tidak relevan di negara berkembang, termasuk Indonesia. ${ }^{2}$ Apalagi setelah terjadi pandemi global yaitu covid-19, ekonomi Indonesia semakin tidak karuan.

Organisasi kesehatan WHO telah mengumumkan pandemi global sejak sekitar bulan Maret 2020. Hampir satu tahun pandemi menyerang negara di seluruh dunia. Salah satunya ialah Indonesia, memasuki tahun 2021 grafik kasus positif covid-19 di Indonesia belum juga menurun justru grafiknya semakin naik. Berikut ini grafik kasus covid-19 di Indonesia dari bulan Desember-Januari:

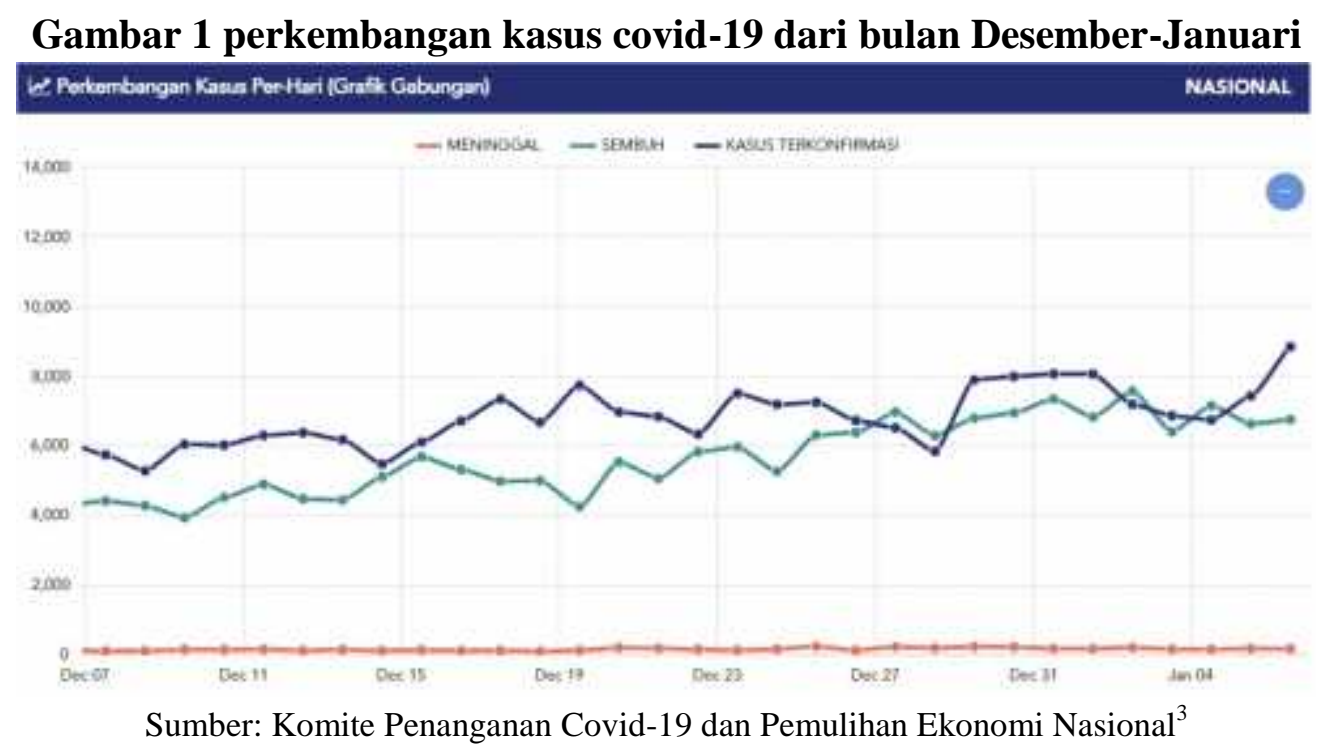

Menteri Keuangan (Menkue) Sri Mulyani Indrawati berharap pemulihan ekonomi nasional sebesar 5\%. Namun pertumbuhan ekonomi tersebut tergantung pengendalian masalah covid-19 melalui vaksin dan kepatuhan masyarakat pada protokol kesehatan. Pemulihan ekonomi menjadi prioritas dalam Anggaran Pendapatan dan Belanja Negara (APBN) 2021. Belanjabelanja negara didesain untuk membangun pondasi ekonomi Indonesia menjadi lebih kuat. Berkaca pada kontraksi yang dialami di kuartal kedua tahun 2020, Menkeu menyatakan alokasi belanja tersebut bertujuan untuk menggerakkan roda ekonomi tahun 2021 dan menjadikan perekonomian Indonesia masuk dalam zona positif. ${ }^{4}$ Rencana dari pemerintah melalui Menteri Keuangan harus mendapat dukungan dari berbagai pihak yang terkait bidang ekonomi. Mengingat aspek-aspek penting dalam ekonomi seperti supply, demand, dan supplycain mengalami gangguan karena pandemi ini. Dampak dari pandemi global ini merata dari kalangan atas sampai ke bawah. Kelompok menengah bawah khususnya mikro dan informal dengan pendapatan harian sangat rentan terkena dampak akibat pandemi ini.

Kebijakan darurat yang berkaitan dengan perekonomian sangat penting dilakukan oleh Pemerintah. Dampak pandemic covid-19 terhadapa berbagai macam lapisan masyarakat akan mengganggu tingkat kesejahteraan. Maka kebijakan terkait Ekonomi Islam perlu dilakukan dengan tujuan-tujuan sebagai berikut: pertama, memaksimalakan segala sumber daya baik itu alam maupun manusia untuk mengatasi dampak pandemic covid-19. Kedua, adanya kerja sama yang baik dari pemerintah dan lembaga kemasyarakatan untuk melakukan distribusi

\footnotetext{
${ }^{2}$ Firmansyah, “Zakat Sebagai Instrumen Pengentasan Kemiskinan Dan Kesenjangan Pendapatan,” Jurnal Ekonomi dan Pembangunan 21, no. 2 (2013): 179-190, https://jurnalekonomi.lipi.go.id/JEP/article/ view/66/26.

${ }^{3}$ Komite penangan covid-19 dan pemulihan ekonomi Nasional, "Peta Sebaran Kasus Covid-19," last modified 2021, accessed January 6, 2021, covid19.go.id.

${ }^{4}$ Sri Mulyani, "Pemulihan Ekonomi Lewat Belanja Dan Pengendalian Covid-19 Masih Jadi Prioritas APBN 2021."
} 
secara adil. Ketiga, pemerintah bisa membuat kebijakan terkait badan usaha-usaha agar tidak mati. Kegiatan tersebut bisa seperti sosial ekonomi. ${ }^{5}$

Melihat kondisi seperti ini, maka akan timbul sebuah pertanyaan besar, Apakah Indonesia mampu melewati masa krisis ini? Karena ini tidak hanya krisis ekonomi tapi yang lebih parah adalah krisi kesehatan. Ada sebuah harapan besar dalam diri bangsa ini. Sebagai negara yang mayoritas penduduknya muslim dan menjadi penduduk muslim terbesar dunia, umat Islam dapat mengambil peran terkait pandemi global.

Di Indonesia sudah banyak model philanthropy yang kaitannya dengan Ekonomi dan Keuangan Syariah. Philanthropy yang dikaitkan dengan Islam berhubungan dengn zakat, infaq, sedekah dan wakaf (ziswaf). Praktik tersebut dikaitkan dengan wacana kedermawanan Islam untuk membantu kesejahteraan secara umum. ${ }^{6}$ Zaman terus mengalami banyak perkembangan dan kemajuan. Namun disisi lain permasalah juga semakin kompleks. Maka sistem manejemen penerimaan dan pendayagunaan Zakat, Infaq, Sedekah dan Wakaf yang pada kajian-kajian fiqih klasik hanya digunakan untuk beberapa masalah saja. Namun dengan berbagai masalah yang sangat kompleks, para ulama mulai berijtihad untuk mengaplikasikan zakat, infaq, sedekah dan wakaf sesuai konteksnya dengan tidak menghilangkan esensinya.

Islam sebagai agama yang rahmatan lil 'alamin, yang penuh kasih sayang dan saling mengasihi. Islam memiliki sebuah konsep yang luar biasa untuk ambil peran dalam kemanusiaan. Diantaranya ada perintah berinfaq, zakat, sedekah dan wakaf sebagai bentuk aplikasi dari keimanan seorang muslim. Output dari aplikasi tersebut adalah mengasihi dan menyayangi dalam bentuk kedermawanan harta. Aplikasi iman dalam bentuk kedermawanan tersebut dapat menjadi problem solution dalam bidang ekonomi, sosial, lingkungan dan pendidikan. Khusus hal ini dapat sebagai penunjang masalah ekonomi akibat pandemi covid19 di Indonesia. Berdasarkan paparan tersebut, penelitian ini dilakukan dengan tujuan mengakaji peran ZISWAF dalam mengatasi masalah ekonomi karena terjadi pandemi covid19.

\section{B. Metode Penelitian}

Penelitian ini menggunakan metode kualitatif diskriptif yaitu upaya untuk mengetahui peristiwa dalam objek penelitian, kemudian dilakukan dengan pendekatan studi pustaka (library research). Studi pustaka (library research) merupakan jenis penelitian yang menggunakan data-data sekunder yang didapatkan dari hasil penelitian, buku, jurnal, artikel yang berkaitan dengan topik penelitian. Sementara untuk menganilisisi data menggunakan teknik content analysis, yaitu suatu metode yang digunakan untuk mengetahui suatu kesimpulan dari sebuah teks.

\section{Hasil dan Pembahasan}

Islam agama yang menentang kemisikan, karena kemiskinan akan mengakibat kekufuran. Hari ini dunia sedang di uji pandemi covid-19. Selain mengancam kesehatan, pandemi covid19 juga mengancam ekonomi. Akibat dari covid-19 banyak para pekerja di PHK, Pedagang diminta mengurangi mobilitsanya karena larangan pemerintah untuk berkerumun. Maka tidak heran angka kemiskinan pada masa pandemi covid-19 semakin meningkat. Badan Pusat

\footnotetext{
${ }^{5}$ Yenti Sumarni, "Manajemen Ekonomi Islam Dalam Menangani Pandemi Coronavirus Disease (COVID19) Di Indonesia,” Jurnal BAABU AL-ILMI: Ekonomi dan Perbankan Syariah 5, no. 1 (2020): 117.

${ }^{6}$ Abu Zahrah, Muhadlarah Fî Al-Waqf (Cairo: Dar al Fikr, 2005); Asnaini and M Izdad Hilmi, "The Relationship of Knowladge on The Perception of Economic Development Zakat Based (PEZ)," Baabu Al-Ilmi 4, no. 2 (2019): 174-185.
} 
Statistik (BPS) menggelar Survei Sosial Demografi Dampak Covid-19. Survei yang diunggah ke bps.go.id pada 1 Juni 2020 ini menggunakan metode NonProbability Sampling yang merupakan kombinasi dari Convenience, Voluntary dan Snowball Sampling dengan total 87.379 responden. Hasil survei menunjukkan bahwa 2,52 persen responden mengaku terkena PHK akibat perusahaan mereka terimbas Covid-19. Sementara, 18,34 persen dirumahkan. Jika berdasarkan jenis kelamin, pekerja laki-laki yang mengaku kena PHK mencapai 3,18 persen dari total responden laki-laki. Sementara, 1,87 persen dari responden perempuan juga mengaku jadi korban PHK. ${ }^{7}$

Dalam instrument ekonomi Islam terdapat pilar-pilar sebagai penunjang sebuah perekomian, yaitu zakat, infak, sedekah dan wakaf (ZISWAF). Ada dua konsep ekonomi yang utama. Mekanisme sharing dapat meningkatkan pertumbuhan ekonomi yang berkeadilan. Tujuan dari ekonomi keadilan adalah untuk meningkatkan kesejahteraan fakir, miskin. Konteks jangka pendek akan mampu membantu fakir miskin memenuhi kebutuhan hidup, sementara dalam konteks jangka panjang dapat menguatkan daya tahan ekonomi sehingga bisa meningkat. ${ }^{8}$ Indonesia kini memasuki masa krisis kesehatan akibat covid-19. Selain krisis kesehatan, akibat covid-19 juga berdampak terhadap ekonomi. Banyaknya pegawai yang di PHK otomatis pengangguran juga bertambah dan otomatis daya beli masyarakat menurun karena tidak ada pemasukan. ${ }^{9}$ Menteri Keuangan (MENKEU) Sri Mulyani menyatakan bahwa kondisi seluruh negara di dunia sedang mengalami krisis ekonomi. Bahkan Sri Mulyani mengungkapkan, kalau Menteri Keuangan Inggris menyebut bahwa kondisi ini terburuk selama 300 tahun terakhir. ${ }^{10}$ Apa yang terjadi di Inggris juga terjadi di Indonesia. Indonesia sebagai mayoritas muslim maka harus bisa memanfaatkan intrumen ekonomi Islam yang bisa di aplikasikan sebagai berikut.

Pertama, Yusuf Qardhawi menyatakan zakat memiliki peran tidak hanya mengentaskan kemiskinan tetapi juga dapat mengantaskan masalah masyarakat lainnya seperti sosial, politik dan lingkungan. Melihat fungsi zakat lebih khusus untuk mengentaskan masalah ekonomi. ${ }^{11}$ Sementara Adiwarman A. Karim menjelaskan bahwa zakat adalah rukun ketiga yang mengajarkan untuk membatasi harta yang telah memenuhi syarat dan ketentuan untuk dikeluarkan kepada yang berhak menerima. ${ }^{12}$ Tujuan inti dari pendistribusian, pemberdayaan, dan sosialisasi zakat untuk mengangkat kelompok fakir-miskin keluar dari kemiskinan, memperbaiki kualitas hidup. Merubah dari status mustahiq menjadi muzakki. ${ }^{13}$ Zakat dalam konteks sekarang bisa berfungsi untuk membantu pemerintah dalam hal masalah ekonomi karena pandemi covid-19. Penyaluran dapat dilakukan kepada delapan kriteria yang berhak menerima zakat (mustahiq) yang terdampak akibat covid-19.

\footnotetext{
${ }^{7}$ Badan Pusat Statistik, "Hasil Survei Sosial Demografi Dampak COVID-19," Badan Pusat Statistik.

${ }^{8}$ Almahmudi, "Implikasi Instrumen Non-Zakat (Infaq, Sedekah, Dan Wakaf) Terhadap Perekonomian Dalam Perkembangan Hukum Ekonomi Syariah."

${ }^{9}$ Ripki Mulia Rahman, "Optimalisasi Ziswaf Sebagai Alternatif Solusi Ketahanan Pangan Di Masa Krisis," Kasaba: Jurnal Ekonomi Islam 13, no. 2 (2020): 108-121, http://ejournal.uika-bogor.ac.id/index.php/KASABA.

${ }^{10}$ Jawa Pos, "Sri Mulyani: 9 Bulan Pandemi Bikin Kontraksi Ekonomi Dunia Dramatis," Jawa Pos, accessed January 20, 2020, https://www.jawapos.com/ekonomi/08/12/2020/sri-mulyani-9-bulan-pandemi-bikinkontraksi-ekonomi-dunia-drastis.

${ }^{11}$ Dwi Wulansari Sintha, "Analisis Peranan Dana Zakat Produktif Terhadap Perkembangan Usaha Mikro Mustahik" (UNDIP, 2013).

${ }^{12}$ Adiwarman Azwar Karim, Fikih Ekonomi Keuangan Islam, Darul Haq. (Jakarta, 2004).

${ }^{13}$ Nur Fadhilah, "Pemberdayaan Komunitas Marjinal Berbasis Zakat Di LPP-Ziswaf Harapan Ummat Malang Jawa Timur,” Dinamika Penelitian 17, no. 1 (2017): 23.
} 
Zakat merupakan instrument wajib dalam sistem ekonomi Islam. Maka dalam aplikasi dilakukan oleh lembagaa legal yang memiliki kekuatan hukum di Indonesia. Hal tersebut dilakukan dalam proses perencanan, pengumpulan, pengelolaan dan pendistribusian bisa sistematik dan terukur. Zakat dalam sejarah telah menjadi bagian peradaban Islam, adapun manfaat bagi perekonomian yaitu: (1) Zakat bisa menjadi solsui bagi masyarakat yang kekurangan (2) Zakat menjadi solusi dan untuk mengatasi kesenjangan di masyarakat (3) Zakat dapat meminimalisir masalah sosial, kriminalitas, pelacuran, pengamis, gelandangan dan lainnya. (4) Zakat dapat menjaga kestabilan ekonomi. Melalui zakat dapat menjaga tingkat konsumsi sehingga perekonomian terus berjalan dan akan tercapai pemerataan ekonomi. $^{14}$

Melihat potensi zakat yang luar biasa, zakat pada tahun 2020 tercatat sebanyak kurang lebih 380 triliun, dan terealisasi sekitar 340 triliun. ${ }^{15}$ Zakat merupakan maaliyah ijtamiyyah yang memiliki peran strategis untuk kesejahteraan dan kemakmuran masyarakat. ${ }^{16}$ Maka untuk mengoptimalkan penghimpunan dan pendistrisbusian zakat, infaq, sedekah dan wakaf bisa diupayakan sebagai berikut: Dalam UU No. 23 Tahun 2011 Tentang pengelolaan Zakat dijelaskan pada pasal 15 ayat 2 bahwa pengumpulan zakat melalui UPZ sebagaimana dimaksud pada ayat (1) dilakukan dengan UPZ pada: 1) Kantor santunan kerja pemerintah daerah kabupaten/kota; 2) Kantor intansi vertikal tingkat kabupaten/kota; 3) Badan usaha milik daerah kabupaten/kota; 4) Perusahaan swastas skala kabupaten/kota; 5) Masjid, musholla, langgar, surau atau nama lainnya; 6) Sekolah/ madrasah dan lembaga pendidikan lain; 7) Kecamatan atau nama lainnya; dan 8) Desa/kelurahan atau nama lainnya. ${ }^{17}$

Berdasarakan undang-undang di atas, sungguh sangat realistis untuk mendirikan UPZ di setiap kantor desa. Karena desa adalah bagian pemerintahan yang paling bawah dan tentunya memiliki nilai jual. Sehingga dalam hal ini bisa mengoptimalkan peran zakat untuk membantu ekonomi masyarakat. Sehingga pendataan terkait mustahiq atau penerima zakat yang terdampak covid-19 bisa lebih terstruktur dan mengena semua lapisan masyarakat. Adanya UPZ ditingkat desa bisa mengoptimalkan dalam rangka mengkampanyekan zakat dengan media yang ada di desa, bisa melalui media online ataupun pejabat desa. Melihat realita bahwa masyarakat desa kurang sadarnya zakat mal. Mayoritas penduduk desa hanya mengetahui zakat fitrah, yang ditunaikan ketika menjelang idul fitri.

Potensi zakat yang dimiiliki Indonesia sangat luar biasa. Jika bisa dikelola dengan profesional maka akan berdampak bagi kesejahteraan masyarakat. ${ }^{18}$ Seperti yang dijelaskan di atas bahwa tingkat pemahaman zakat rakyat Indonesia masih rendah. Pemerintah harus merespon hal tersebut, dari tingkatan desa diharapkan akan mengoptimalkan peran zakat sebagai jaminan kesejahteraan masyaraka. ${ }^{19}$ Tujuan utama dari pendistribusian, pemberdayaan, dan sosialisasi zakat untuk mengangkat kelompok fakir-miskin keluar dari kemiskinan, memperbaiki kualitas hidup. Merubah dari status mustahiq menjadi muzakki.

\footnotetext{
${ }^{14}$ Awang Darmawan and Rina Desiana, "Zakat Dan Pemerataan Ekonomi Di Masa Pandemi COVID-19," Al - Azhar Journal of Islamic Economics 3, no. April (2021): 12-24, http://dx.doi.org/10.20885/jielariba.

${ }^{15}$ Gita Amanda, "Ziswaf Dan Resesi Ekonomi Di Era Pandemi," Baznas. Go.Id.

${ }^{16}$ Nurul Huda and Dkk, Perspektif Makro-Mikro (Jakarta: Prenamedia Group, 2015).

${ }^{17}$ Undang-Undang No.23 Tahun 2011 Tentang Pengelolaan Zakat, 2011.

${ }^{18}$ Arin Setiyowati, "Analisis Peranan Pengelolaan Dana Ziswaf Oleh Civil Society Dalam Pemberdayaan Ekonomi Umat (Studi Kasus Lazismu Surabaya),” Jurnal Ekonomi dan Perbankan Syariah 2, no. 1 (2017).

${ }^{19}$ Abdul Ghofur and Noor Ruslan, Konsep Distribusi Dalam Ekonomi Islam: Format Keadilan Ekonomi Di Indonesia (Yogyakarta: Pustaka Pelajar, 2013).
} 
Kedua, menurut UU No. 41 Tahun 2004 wakaf merupakan ibadah dalam bentuk melepas atau menyerahkan sebagian harta agar bisa dimanfaatkan untuk kepentingan umum atau kesejahteraan umum menurut ketentuan Syariah. ${ }^{20}$ Sementara waqaf dalam perspektif ekonomi merupakan pengalihan dana asset baik bergerak maupun diam yang dialokasikan ke dalam aset produktif untuk dikonsumsi pada masa yang akan datang dengan secara individual maupun kelompok. ${ }^{21}$ Wakaf tidak hanya benda diam, tapi dalam konteksnya bisa berbentuk wakaf tunai dan wakaf produktif. Namun, pada dasarnya aset (tanah) waqaf tidak boleh dirubah, kecuali waqaf tersebut tidak bisa dimanfaatkan lagi. Maka terhadap waqaf yang berkaitan bisa diadakan perubahan penggunaan dengan tujuan yang sama. ${ }^{22}$

Badan Wakaf Indonesia (BWI) perlu bergandengan dengan Lembaga Keuangan Syariah (LKS) untuk mengkampanyekan terkait wakaf tunai maupun wakaf produktif. Para ulama telah membahas terkait kelegalan bentuk wakaf tersebut yaitu dianjurkan (sunnah). ${ }^{23}$ Hari ini tercacat bahwa pontesi terkait wakaf uang sangat potensial. Lembaga-lembaga wakaf harus punya inisiatif untuk berinovasi agar bisa mengumpulkan wakaf uang dan diproduktikan menurut ajaran Islam. Dimana laba yang dihasilkan bisa untuk membiayai sektor-sektor yang membutuhkan. ${ }^{24}$ Dalam konteks masa pandemi covid-19 dapat dimanfaatkan untuk pembangunan insfrastruktur rumah sakit, pembelian alat pelindung diri (APD), masker, alat rapid test, tempat isolasi, vaksin dan lainnya yang berbasis wakaf. Realita hari ini wakaf hanya sebatas benda mati, kurang dimanfaatkan atau diproduktifkan secara professional.

Dalam kondisi ekonomi Indonesia yang masih memprihatikan, meskipun sumber daya alam dan manusia yang sangat luar biasa tapi belum bisa berbuat banyak terkait pertumbuha ekonomi. Wakaf bisa menjadi salah satu solusi yang signifikan untuk memperdayakan ekonomi masyarakat. ${ }^{25}$ Padahal potensi dari wakaf sangat luar biasa. Potensi harta wakaf yang dimiliki bangsa Indonesia sebanyak 2.686.536.565,68 $\mathrm{m}^{2}$ yang tersebar di 366.595 lokasi. ${ }^{26}$ Namun sayangnya potensi tersebut belum dikelola dengan baik seperti yang telah dicontohkan beberapa negeri di timur tengah, sehingga akan berimbas peningkatkan pertumbuhan ekonomi yang akan menciptakan kesejahteraan untuk masyarakat. Bentuk nyata dari pemanfaatan wakaf secara profesional adalah Universitas Al-Azhar Kairo, Mesir. Wakaf di Kairo bisa untuk membiayai pendidikan gratis bagi semua pelajar yang datang dari penjuru dunia.

Ketiga, pengelolaan infaq dan sedekah yang profesional akan berdampak positif bagi masyarakat luas. Pengelolaan infaq dan sedekah dengan zakat sebenarnya tidak jauh berbeda, perbedaanya hanya pada perkara hukum. Zakat menjadi wajib kaluar telah mencapai nisab dan haul yang telah ditentukan, sementara hukum infaq dan sedekah adalah sunnah. ${ }^{27}$ Lembaga yang bergerak di bidang infaq, sedekah, zakat dan wakaf harus bersinergi dengan

\footnotetext{
${ }^{20}$ Abdul Nasir Khoerudin, "Tujuan Dan Fungsi Wakaf Menurut Para Ulama Dan Undang-Undang Di Indonesia," TAZKIYA 19, no. 2 (2018): 1-10.

${ }^{21}$ Farid Wajid, Wakaf Dan Kesejahteraan Umat: Filantropi Islam Yang Hampir Terlupakan (Yogyakarta: Pustaka Pelajar, 2007).

${ }^{22}$ Achmad Djunaidi and Thobie Al-Asyhar, Menuju Era Wakaf Produktif, ed. Mumtaz Publishing, 4th ed. (Jakarta, 2007).

${ }^{23}$ M. Wahib Aziz, "Wakaf Tunai Dalam Perspektif Hukum Islam," International Journal Ihya' 'Ulum alDin 19, no. 1 (2017): 1.

${ }^{24}$ Choirunnisak Choirunnisak, "Optimalisasi Wakaf Di Indonesia," Jurnal BAABU AL-ILMI: Ekonomi dan Perbankan Syariah 4, no. 1 (2019): 120.

${ }^{25}$ Ahmad Atabik, "Manajemen Pengelolaan Wakaf Tunai Di Indonesia," Ziswaf 1, no. 1 (2016): 82-107.

${ }^{26}$ Firman Muntaqo, "Problematika Dan Prospek Wakaf Produktif Di Indonesia," Al-Ahkam 1, no. 25 (2015): 83.

${ }^{27}$ S Khalid, Fikih Imam Syafi'i Puasa Dan Zakat, Pustaka Az. (Jakarta, 2004).
} 
lembaga keuangan syariah untuk memaksimalkan penghimpunan infaq dan sedekah. ${ }^{28}$ Adanya dukungan dari lembaga non formal seperti mushola, masjid sangat mendukung untuk menghimpun dana infaq dan sedekah yang dikumpulkan dan dikelola secara nasional oleh BAZNAS. $^{29}$

Salah satu indikasi pengelolaan dana zakat, infaq dan sedekah yang optimal yaitu dapat menciptakan perkembangan perekonomian di Masyarakat. Proses dalam mewujudkan pengelolaan zakat, infaq dan sedekah yang optimal bisa mengacu pada UU No.23 Tahun 2011. Dimana prosedur berdasarkan kerangka yaitu: (1) perencanan (planning), pengorganisian (organizing), (3) penggerakan (actuating), (4) pengawasan (controlling). ${ }^{30}$

Di tengah krisis seperti ini, tidak sedikit usaha-usaha kecil yang gulung tikar. Adanya bantuan modal usaha akan sangat berarti bagi mereka para pelaku usaha kecil. Kelompok usaha kecil yang non muzakki sangat rentan gulung tikar dan jatuh ke jurang kemiskinan. Dengan adanya bantuan modal usaha dari lembaga zakat yang bersinergi dengan lembaga keuangan syariah, diharapkan dapat membantu permasalahan ekonomi akibat pandemi supaya jumlah mustahiq tidak terus meningkat.

Keempat, sistem ekonomi dan keuangan syariah banyak memiliki manfaat yang penuh dengan nilai-nilai kemanusiaan didalamnya. Oleh karena itu, masyarakat sangat perlu diedukasi agar pemahaman tentang ekonomi dan keuangan syariah benar. Maka adanya pengadaan bantuan pendidikan dengan instrument zakat, infaq, sedekah dan wakaf (ziswaf) kepada mahasiswa yang terkena dampak covid-19 sangat relevan, meski dana ziswaf bisa untuk semua mahasiswa dengan latar belakang jurusan apapun asalkan memenuhi kriteria. Namun, dalam rangka mengkampanyekan dan meningkatkan literasi masyarakat terhadap ekonomi dan keuangan syariah, maka bantuan pendidikan yang diutamakan adalah mahasiswa yang jurusannya berkaitan dengan ekonomi syariah.

Berdasarkan Statistik Zakat Nasional Tahun 2018 pertumbuhan pengumpulan ZIS di Indonesia pada rentang kurun waktu tahun 2002-2018 mencapai rerata 34,82 persen, sementara pertumbuhan PDB di Indonesia pada rentang kurun waktu yang sama mencapai rerata 5,38 persen. Pada tahun 2018 tercatat ZIS yang dikumpulkan mencapai Rp 8,1 triliun yang sebagian besarnya dihimpun dari zakat penghasilan sebesar 40,68 persen. Memang jika dibandingkan dengan potensi zakat sebesar Rp 233,8 triliun (Puskas BAZNAS), maka realisasinya pengumpulan masih sangat kecil yakni sekitar 3,4 persen. ${ }^{31}$

Melihat data di atas, bahwa peran ziswaf dalam pertumbuhan ekonomi secara mikro maupun makro cukup baik meski presentasenya masih sangat kecil. Pada akhirnya jika progam-progam di atas bisa terlaksana, baik untuk masyarakat, pengusaha kecil dan mahasiswa maka diharapkan meningkatkan demand dan supply untuk membantu percepatan pemulihan ekonomi nasional akibat covid-19. Selain itu, kedepannya diharapkan jumlah muzakki meningkat dan presentase masyarakat melek literasi ziswaf meningkat dengan begitu otomatis jumlah mustahiq juga menurun.

Manfaat dari zakat, infaq, sedekah dan wakaf terkait perekonomian masyarakat sangat jelas. Dalam zakat, infaq, sedekah dan wakaf (ziswaf) terdapat instrument untuk memberikan

${ }^{28}$ Toha Afifudin and Nurma Sari, "Pengaruh Zakat Dan Infaq Terhadap Penurunan Kemiskinan Di Aceh Periode 2007-2017," Jurnal Ekonomi Dan Bisnis Islam 4, no. 1 (2019): 34-51.

${ }^{29}$ Dewi Purwanti, "Pengaruh Zakat, Infak, Dan Sedekah Terhadap Pertumbuhan Ekonomi Indonesia," Jurnal Ilmiah Ekonomi Islam 6, no. 1 (2020): 101.

${ }^{30}$ Silvi Mariroh and Khoirul Anwar, "Pengelolaan Zakat, Infaq, Dan Sedekah Dalam Pengembangan Usaha Mikro Di Baznas Gresik,” Jurnal Ekonomika Dan Bisnis Islam 3, no. 3 (2020): 114-125.

${ }^{31}$ Amanda, "Ziswaf Dan Resesi Ekonomi Di Era Pandemi." 
perhatian atau bantuan kepada delapan asnaf zakat dan untuk mewujudkan kesejahteraan yang bersifat umum. Hal tersebut dapat dicermati dari pos-pos pendistribusian, dimana ada penyaluran harta dari orang-orang kaya kepada orang fakir. Dengan cara seperti ini, maka terdapat unsur pemerataan kekayaan, sehingga kekayaan tidak menggelembung di pihak tertentu, sementara masih adanya kemelaratan di pihak lain. ${ }^{32}$ Adapun salah satu indikasi terkait berhasilnya pemberdayaan dengan Ziswaf adalah menurunnya angka kemiskinan. Hal ini bisa bermakna bahwa jumlah mustahiq berkurang dan jumlah muzakki bertambah karena meningkatnya tingkat pendapatan masyarakat. ${ }^{33}$

\section{Simpulan}

Indonesia dengan negara mayoritas muslim sekaligus sebagai negara dengan penduduk muslim terbanyak dunia. Umat Islam di Indonesia bisa memberikan perannya dengan model bentuk philanthropy yang bisa kerja sama dengan lembaga keuangan Syariah (LKS), khususnya dalam masa pandemi covid-19. Peran tersebut diharapkan bisa membantu terkait masalah ekonomi sehingga menjadi kabar gembira akibat pandemi covid-19. Adapun solusi yang ditawarakan sebagai berikut: (1) Menjadikan setiap desa sebagai UPZ untuk memaksimalkan zakat (2) memaksimalkan zakat tunai dan zakat produktif (3) memaksimalkan pengelolaan zakat dan infaq (4) mengadakan bantuan pendidikan bagi mahasiswa yang terkena dampak covid-19, yang diutamakan bagi mahasiswa jurusan ekonomi syariah supaya kedepan dapat mengedukasi masyarakat tentang ekonomi Islam. Jika progam-progam tersebut dapat terlaksana diharapkan dapat membantu percepatan pertumbuhan ekonomi di Indonesia.

\section{Daftar Pustaka}

Adiwarman Azwar Karim. Fikih Ekonomi Keuangan Islam. Darul Haq. Jakarta, 2004.

Afifudin, Toha, and Nurma Sari. "Pengaruh Zakat Dan Infaq Terhadap Penurunan Kemiskinan Di Aceh Periode 2007-2017." Jurnal Ekonomi Dan Bisnis Islam 4, no. 1 (2019): 34-51.

Almahmudi, Nufi Mu’tamar. "Implikasi Instrumen Non-Zakat (Infaq, Sedekah, Dan Wakaf) Terhadap Perekonomian Dalam Perkembangan Hukum Ekonomi Syariah." Al Huquq : Journal of Indonesia Islamic Economic Law 2, no. 1 (2020): 30-47.

Amanda, Gita. “Ziswaf Dan Resesi Ekonomi Di Era Pandemi.” Baznas.Go.Id.

Asnaini, and M Izdad Hilmi. "The Relationship of Knowladge on The Perception of Economic Development Zakat Based (PEZ).” Baabu Al-Ilmi 4, no. 2 (2019): 174185.

Atabik, Ahmad. "Manajemen Pengelolaan Wakaf Tunai Di Indonesia." Ziswaf 1, no. 1 (2016): 82-107.

Aziz, M. Wahib. "Wakaf Tunai Dalam Perspektif Hukum Islam.” International Journal Ihya' 'Ulum al-Din 19, no. 1 (2017): 1.

\footnotetext{
${ }^{32}$ Almahmudi, "Implikasi Instrumen Non-Zakat (Infaq, Sedekah, Dan Wakaf) Terhadap Perekonomian Dalam Perkembangan Hukum Ekonomi Syariah."

${ }^{33}$ Dhany Hermawan dan Atep Hendang Waluya, Peran Zakat, Infaq Dan Sedekah Dalam Pemberdayaan Masyarakat Miskin Di KAbupaten Tanggerang, UNMUH Tanggerang, 2018.
} 
Choirunnisak, Choirunnisak. "Optimalisasi Wakaf Di Indonesia." Jurnal BAABU AL-ILMI: Ekonomi dan Perbankan Syariah 4, no. 1 (2019): 120.

Darmawan, Awang, and Rina Desiana. "Zakat Dan Pemerataan Ekonomi Di Masa Pandemi COVID-19." Al - Azhar Journal of Islamic Economics 3, no. April (2021): 12-24. http://dx.doi.org/10.20885/jielariba.

Djunaidi, Achmad, and Thobie Al-Asyhar. Menuju Era Wakaf Produktif. Edited by Mumtaz Publishing. 4th ed. Jakarta, 2007.

Fadhilah, Nur. "Pemberdayaan Komunitas Marjinal Berbasis Zakat Di LPP-Ziswaf Harapan Ummat Malang Jawa Timur.” Dinamika Penelitian 17, no. 1 (2017): 23.

Firmansyah. "Zakat Sebagai Instrumen Pengentasan Kemiskinan Dan Kesenjangan Pendapatan." Jurnal Ekonomi dan Pembangunan 21, no. 2 (2013): 179-190. https://jurnalekonomi.lipi.go.id/JEP/article/view/66/26.

Ghofur, Abdul, and Noor Ruslan. Konsep Distribusi Dalam Ekonomi Islam: Format Keadilan Ekonomi Di Indonesia. Yogyakarta: Pustaka Pelajar, 2013.

Huda, Nurul, and Dkk. Perspektif Makro-Mikro. Jakarta: Prenamedia Group, 2015.

Khalid, S. Fikih Imam Syafi’i Puasa Dan Zakat. Pustaka Az. Jakarta, 2004.

Khoerudin, Abdul Nasir. "Tujuan Dan Fungsi Wakaf Menurut Para Ulama Dan UndangUndang Di Indonesia.” TAZKIYA 19, no. 2 (2018): 1-10.

Mariroh, Silvi, and Khoirul Anwar. "Pengelolaan Zakat, Infaq, Dan Sedekah Dalam Pengembangan Usaha Mikro Di Baznas Gresik." Jurnal Ekonomika Dan Bisnis Islam 3, no. 3 (2020): 114-125.

Mulyani, Sri. "Pemulihan Ekonomi Lewat Belanja Dan Pengendalian Covid-19 Masih Jadi Prioritas APBN 2021."

Muntaqo, Firman. "Problematika Dan Prospek Wakaf Produktif Di Indonesia." Al-Ahkam 1, no. 25 (2015): 83.

Nasional, Komite penangan covid-19 dan pemulihan ekonomi. "Peta Sebaran Kasus Covid19.” Last modified 2021. Accessed January 6, 2021. covid19.go.id.

Pos, Jawa. "Sri Mulyani: 9 Bulan Pandemi Bikin Kontraksi Ekonomi Dunia Dramatis." Jawa Pos. Accessed January 20, 2020. https://www.jawapos.com/ekonomi/08/12/2020/srimulyani-9-bulan-pandemi-bikin-kontraksi-ekonomi-dunia-drastis.

Purwanti, Dewi. "Pengaruh Zakat, Infak, Dan Sedekah Terhadap Pertumbuhan Ekonomi Indonesia." Jurnal Ilmiah Ekonomi Islam 6, no. 1 (2020): 101.

Rahman, Ripki Mulia. "Optimalisasi Ziswaf Sebagai Alternatif Solusi Ketahanan Pangan Di Masa Krisis." Kasaba: Jurnal Ekonomi Islam 13, no. 2 (2020): 108-121. http://ejournal.uika-bogor.ac.id/index.php/KASABA.

Setiyowati, Arin. "Analisis Peranan Pengelolaan Dana Ziswaf Oleh Civil Society Dalam Pemberdayaan Ekonomi Umat (Studi Kasus Lazismu Surabaya)." Jurnal Ekonomi dan Perbankan Syariah 2, no. 1 (2017). 
Sintha, Dwi Wulansari. "Analisis Peranan Dana Zakat Produktif Terhadap Perkembangan Usaha Mikro Mustahik.” UNDIP, 2013.

Statistik, Badan Pusat. "Hasil Survei Sosial Demografi Dampak COVID-19.” Badan Pusat Statistik.

Sumarni, Yenti. "Manajemen Ekonomi Islam Dalam Menangani Pandemi Coronavirus Disease (COVID-19) Di Indonesia." Jurnal BAABU AL-ILMI: Ekonomi dan Perbankan Syariah 5, no. 1 (2020): 117.

Wajid, Farid. Wakaf Dan Kesejahteraan Umat: Filantropi Islam Yang Hampir Terlupakan. Yogyakarta: Pustaka Pelajar, 2007.

Waluya, Dhany Hermawan dan Atep Hendang. Peran Zakat, Infaq Dan Sedekah Dalam Pemberdayaan Masyarakat Miskin Di KAbupaten Tanggerang. UNMUH Tanggerang, 2018.

Zahrah, Abu. Muhadlarah Fî Al-Waqf. Cairo: Dar al Fikr, 2005.

Undang-Undang No.23 Tahun 2011 Tentang Pengelolaan Zakat, 2011. 